\title{
Exploring Resistance in Collaborative Forms of Governance Meaning Negotiations and Counter-narratives in a Case from the Danish Education Sector
}

\author{
Plotnikof, Mie; Pedersen, Anne Reff
}

Document Version

Accepted author manuscript

Published in:

Scandinavian Journal of Management

DOI:

10.1016/j.scaman.2019.101061

Publication date:

2019

License

CC BY-NC-ND

Citation for published version (APA):

Plotnikof, M., \& Pedersen, A. R. (2019). Exploring Resistance in Collaborative Forms of Governance: Meaning Negotiations and Counter-narratives in a Case from the Danish Education Sector. Scandinavian Journal of Management, 35(4), [101061]. https://doi.org/10.1016/j.scaman.2019.101061

Link to publication in CBS Research Portal

\section{General rights}

Copyright and moral rights for the publications made accessible in the public portal are retained by the authors and/or other copyright owners and it is a condition of accessing publications that users recognise and abide by the legal requirements associated with these rights.

\section{Take down policy}

If you believe that this document breaches copyright please contact us (research.lib@cbs.dk) providing details, and we will remove access to the work immediately and investigate your claim. 


\title{
Exploring Resistance in Collaborative Forms of Governance: Meaning Negotiations and Counter-narratives in a Case from the Danish Education Sector
}

\author{
Mie Plotnikof and Anne Reff Pedersen
}

Journal article (Accepted manuscript*)

\section{Please cite this article as:}

Plotnikof, M., \& Pedersen, A. R. (2019). Exploring Resistance in Collaborative Forms of Governance: Meaning Negotiations and Counter-narratives in a Case from the Danish Education Sector. Scandinavian Journal of

Management, 35(4), [101061]. https://doi.org/10.1016/j.scaman.2019.101061

DOI: https://doi.org/10.1016/j.scaman.2019.101061

* This version of the article has been accepted for publication and undergone full peer review but has not been through the copyediting, typesetting, pagination and proofreading process, which may lead to differences between this version and the publisher's final version AKA Version of Record.

Uploaded to CBS Research Portal: August २०२०

(c) 2019. This manuscript version is made available under the CL-BY-NC-ND 4.0 license http://creativecommons.org/licenses/by-nc-nd/4.0/ 


\section{Exploring resistance in collaborative forms of governance:}

\section{Meaning negotiations and counter-narratives in a case from the Danish education sector}

\section{Introduction}

Governance research has diagnosed changes in public sector organizing: from the dominance of hierarchical and market-based structures to the inclusion of various cross-sectoral collaborations in networks and partnerships (Bryson, Crosby, \& Stone, 2015; O’Leary \& Vij, 2012; Osborne, 2006). Such collaborative forms of governance are intended to address societal issues, such as changing demography, education and health care, through involving relevant stakeholders in policy and service innovation. Despite such potentials, there are also considerable challenges when a diversity of actors with different stakes collaborate to find solutions to such issues (Cinar, Trott, \& Simms, 2019). A stream of governance studies particularly stress issues of social dynamics: tensions, conflicts, and (mis-)communication (Hardy, Lawrence, \& Grant, 2005; Huxham \& Vangen, 2000; Mangan, Thomas, Davies, \& Gasper, 2018; Plotnikof, 2016b; Purdy, 2012). Despite this research on the challenges of public sector collaboration, resistance remains largely unexplored in the literature; when addressed, it is considered destructive misbehaviour (Kumar, Kant, \& Amburgey, 2007). However, given that collaboration to find new governance responses to such challenges are idealized within certain strands of governance theory (Ansell \& Torfing, 2014; Bryson et al., 2015; Hartley, Sørensen, \& Torfing, 2013), resistance is a potentially sore, yet critical aspect to grasp (Mumby \& Plotnikof, 2019). Furthermore, in practice, both human and economic resources are at stake in collaborations addressing public issues, making it likely that struggles of power and resistance will emerge (Hardy et al., 2005). As such, overlooking resistance may prove counter-productive and have a strengthening rather than minimizing effect (Mumby, Thomas, Martí, \& Seidl, 2017). 
This paper therefore explores resistance in collaborative governance studies and practices without approaching it as inherently negative. Drawing on resistance studies, we define resistance as a discursive struggle over meanings "that is always open-ended, always characterized by an excess of signification that makes available possibilities of constructing alternative, resistant, counterhegemonic accounts of organizing” (Mumby, 2005: 33). Thus, we view resistance as a productive force in a dynamic relation to power, co-constitutive of organizing governance (Erkama, 2010; Grant \& Marshak, 2011; Thomas \& Hardy, 2011). Based on this, we ask how resistance emerges in discursive struggles of collaborative forms of governance in a case from the Danish education sector. To explore such struggles in everyday communication, we develop an analytical approach that combines the concepts of meaning negotiation (Plotnikof, 2015; Thomas, Sargent, \& Hardy, 2011) and counter-narrative (Frandsen, Kuhn, \& Lundholt, 2016; Humle \& Pedersen, 2015). Whereas the former attends to ongoing negotiations of local collaborative governance meanings and practices, the latter focuses on how those negotiations embody power-resistance relations between dominant and counter-narratives of collaboration (Grant \& Marshak, 2011). Recognizing that resistance is a complex phenomenon not easily captured empirically (Prasad \& Prasad, 2000), our approach focuses on the everyday work of organizing collaborative forms of governance.

This approach allows us to investigate resistance as discursive struggles in meaning negotiations and counter-narratives in a Danish case study of collaboration in early childhood education (ECE) governance. In Denmark, ECE is a central policy area governed by national legislation that is of great public concern; 90-98\% of all children in this age group are enrolled in ECE centres. The ECE sector thus has a considerable budget and enables a more gender-equal labour market (Plum, 2012). Despite the dominance of hierarchically structured educational governance, collaborative tendencies are also emerging. The case study concerns a local government's collaborative initiative to innovate ECE policy and services with quality ideals of visible, efficient learning and $21^{\text {st }}$ century technological 
skills (Hattie, 2008; Knudsen, 2017). Through ethnographic fieldwork across both administrative and educational contexts, we collected data over a six-month period during collaborations between stakeholders such as politicians, administrators, ECE managers, and staff. The collaborations, however, also involved resistance during both the planning and collaborative processes.

In advancing the understanding of resistance dynamics in studies of collaborative forms of governance, we theorize resistance as discursive struggles over and within collaboration, which we analytically conceptualize as meaning negotiations and counter-narratives. Furthermore, through qualitative analysis of a local case of collaborative governance in the ECE sector, we examine how a dominant narrative of collaboration to improve ECE quality is challenged by meaning negotiations and counter-narratives communicating various modes of resistance, both direct and indirect. In our case study, this influences the organizing of the local governance initiative without destroying it. Instead, power-resistance relations of hierarchical and collaborative discourses invoked by meaning negotiations and counter-narratives during this initiative unsettle and legitimize multiple meanings of collaborative processes and purposes for a new model of ECE quality, both prior to and during collaborative events. This affects stakeholders' selection of collaborative themes and goals to include multiple, even conflicting, voices in future collaborations. Thus, instead of viewing resistance as a destructive attitude, we suggest it be understood as interwoven into collaborative forms of governance, which thereby rely on diversity (of actors, organizations, stakes, etc.) and a divergence of meanings when seeking to co-create solutions. We therefore view collaborative forms of governance as fragmented, even contradictory, organizing processes.

In the following, we first address governance studies of collaborative challenges, before turning our attention to resistance studies on organizational discourses and counter-narratives to develop our approach. Next, we present the case of ECE governance in Denmark, and the research methods 
applied. We then unpack the findings in a two-stage analysis, and present a concluding discussion of the contributions to and implications for research and practice.

\section{Governance studies of collaborative challenges}

This paper addresses resistance in governance studies of collaborative arrangements defined by an engagement "across the boundaries of public agencies, levels of government, and/or the public, private and civic spheres in order to carry out a public purpose that could not otherwise be accomplished" (Emerson, Nabatchi, \& Balogh, 2012, p. 2). This definition encompasses concepts of collaborative governance, collaborative public management, co-production, and cross-sector collaboration and partnerships that, despite various nuances, all demarcate inter-organizational governance processes of stakeholder collaboration to address shared problems (Ansell \& Gash, 2008; Bryson et al., 2015; O’Leary \& Vij, 2012; Vangen \& Huxham, 2012). In this paper, we refer to such processes as collaborative forms of governance (abbreviated to CG), and it is within this scope that our study of resistance is framed, as such types of governance manifest not just potentials, but indeed also challenges to theory and practice. Below, we address governance research concerned with challenges closely related to resistance, such as socially dynamic tensions of diverse work cultures, languages, and power (Hardy et al., 2005; Huxham \& Vangen, 2000; Purdy, 2012).

Only one governance study explicitly examines resistance in relation to collaboration. This study uses measurements of attitude and behaviour to explicitly examine the human elements of resistance during collaboration (Kumar et al., 2007). This enables an exploration of "how individuals within public agencies resist or accept the idea of public participation and what various factors influence the degree of attitudinal resistance or acceptance” (p. 570). This approach to resistance on a 'human level' is conceptualized through an individualistic, cognitive orientation, which results in a structural 
equation model of attitudes and behaviours. In effect, the study thereby reduces the human elements to a primarily individual matter. Although it offers specific behavioural measurements of resistance, by conceptualizing individual attitudes it overlooks more socially dynamic features. Furthermore, it only explains resistance in dualistic terms - 'acceptance' versus 'resistance' - without attending to the tensional dynamics of collaboration. Resistance thus becomes a destructive obstacle, a lack of adaptability amongst individual actors that must be managed. Such a model constructs explanations for individual or cognitive aspects of resistance, but it overlooks the socially dynamic aspects at play during collaboration.

Another strand of governance studies particularly stresses socially dynamic issues during CG through concepts such as tension, power and discourse; however, these studies do not explicitly theorize resistance. Vangen and colleagues theorize collaborative tensions and paradoxes and discuss how “managerial responses need to incorporate these” (Vangen \& Huxham, 2012, p. 757). They develop the concept of 'paradox' in order to unpack the nexus of common and conflicting collaborative goals. Elsewhere, they (Vangen \& Winchester, 2013) conceptualize management tensions in relation to cultural diversity and conflicts - in terms of e.g. different languages and misunderstandings during collaboration. They suggest such collaborative challenges be approached as ongoing tensions that collaborative managers should draw upon rather than to overcome. Thereby, they offer dynamic concepts for dealing with diversity in collaboration, but without explaining resistance. Purdy (2012), followed by Plotnikof (2016a), Dewulf and Elbers (2018), study power-infused tensions through a theory of collaborative power, using concepts of power sources and arenas - including authority, resources and discourse - to understand power dynamics in collaboration. These studies stress discursive power because actors’ production of legitimacy affects the collaboration; for example, how they inform, (mis-)communicate and produce/reduce meanings of collaboration. However, these studies do not explore how discursive power may construct not only legitimacy, but also resistance. 
A few other studies likewise link the challenges of CG to (mis-)communication and discourse (Hardy et al., 2005; Koschmann et al., 2012; Mangan et al., 2018). Hardy, Lawrence and Grant (2005) develop a discourse model of identity and negotiations, arguing that collaboration "depends on the relationships among participating members, which are negotiated on an ongoing basis throughout the life of the collaboration. Consequently, collaboration represents a complex set of ongoing communicative processes among individuals” (2005, p. 59). They conceptualize text-conversation dialectics as discursive processes that politicize and (il)legitimize collaborative meanings and may create collective or fragmented identities. This implies the potential for resistance, e.g. between dominant and counter-meanings. However, the model does not offer an explanation for resistance; a shortcoming the authors call on future research to address (2005, p. 73). Another study of collaborative communication also conceptualizes text-conversation dialectics in order to understand the communicative constitution of collaboration and its potential value (Koschmann et al., 2012). This study argues for the necessity of unpacking complex communicative practices that coordinate and control collaboration (2012, pp. 336; 339), but despite its detailed model and its concern with how actors compete to influence collaboration, it only hints at resistance.

In sum, only one study has explicitly addressed resistance in terms of a structural equation model, but despite its behavioural measurements, this study overlooks the complex social aspects of resistance that are discursively grounded in interaction and communication about and during collaboration (Mumby, 2005; Mumby \& Plotnikof, 2019). Other studies on collaborative challenges view issues of social dynamics as critical to collaborative failure and success. However, although they contribute to a better understanding of the challenges of organizing CG, resistance remains largely unexplored in the literature, and is therefore a phenomenon that calls for greater scrutiny.

\section{Approaching resistance as discursive struggle: meaning negotiation and counter-narrative}


To this end, we build on resistance studies (Erkama \& Vaara, 2010; Mumby et al., 2017), especially those concerned with organizational discourse and counter-narratives (Frandsen et al., 2016; Mumby, 2005; Thomas et al., 2011) as these concepts are well-suited to an exploration of resistance in collaboration (Mumby \& Plotnikof, 2019). Aligned with Hardy et al. (2005), and Koschmann et al. (2012), we view discourse as constructing the social reality of CG through communication, rather than reflecting it. Following their definitions, communication encompasses dialectics of texts and conversations: “Conversations are observable interactions-the 'site' where organization is accomplished and experienced [...] Texts, in turn, are the symbolic 'surface' upon and through which conversations develop; they are how organizational forms are identified, described, and represented.” (Koschmann et al., 2012, p. 335). As such, text-conversation dialectics enact discourses defined as sets of "interrelated texts and their related practices of consumption, production, and distribution which bring into being an object or idea.” (Hardy et al., 2005, p. 61). Thus, communication embodies discourse in everyday life, thereby constructing local version of CG.

Many discourse studies on resistance use similar definitions and view resistance as dynamically emerging in struggles over meaning and practice (Mumby \& Plotnikof, 2019; Thomas \& Hardy, 2011). This is in contrast to dominant views of resistance as a destructive problem to be managed much like what we saw in Kumar et al.'s (2007) work. Instead, discourse studies see resistance as a constructive dynamic and conceptualize it in terms of, for example, meaning negotiations, multi-story processes, and counter-narratives (Buchanan \& Dawson, 2007; Grant \& Marshak, 2011; Thomas et al., 2011). Inspired by Foucault, such concepts focus on the dynamic relation between resistance and power; that is, power as a generative rather than an oppressive force (Buchanan \& Dawson, 2007; Foucault, 1980, 1994; Grant \& Marshak, 2011; Plotnikof, 2015; Thomas et al., 2011). To move beyond a destructive concept of resistance, these studies stress: “[t]here are no relations of power without resistance. Resistance is an adaptive response to power, it operates in tandem with power, 
and it forms at the points where relations of power are exercised” (Thomas \& Hardy, 2011, p.326). In line with this, we understand resistance as intrinsic to power relations and defined by discursive struggles over meanings and practices that, through communication, counter and challenge dominant narratives, and hence enable multiple accounts of organizing local realities (Mumby, 2005). In this view, discursive power production in collaboration, for instance shaping a dominant narrative of collaboration (Purdy, 2012; Grant et al., 2005), is not an end state; rather, it is part of the ongoing local accomplishment of collaboration - and dynamically interwoven with potential resistance. It follows that neither power nor resistance are absolute; instead, they are in tension with one another, and may be voiced, enacted or otherwise communicated through a variety of modes, such as ironic distance, direct confrontation or hidden alliances (Mumby et al., 2017; Prasad \& Prasad, 2000), as they intertwine and struggle in everyday work life.

To better understand such complex resistance dynamics in CG, we propose to study them through the discursive struggles communicated in meaning negotiations and counter-narratives of and during collaboration. We define meaning negotiations as communication negotiating more or less divergent meanings and practices and embodying discursive tensions between them (Thomas \& Hardy, 2011; Thomas et al., 2011). Meaning negotiations may embody resistance dynamics in everyday communication, although not necessarily in a directly oppositional, aggressive or destructive way. Rather, they can involve struggles and counter-narratives that enable or enact resistance in more indirect, non-strategic or unnoticed ways (Mumby et al., 2017; Plotnikof, 2015; Prasad \& Prasad, 2000). This implies that collaborative communication is not necessarily consensus-driven, but likely infused with power-resistance relations between different, even conflicting, understandings that can affect collaborative processes, e.g. by legitimizing new perspectives or enabling further negotiations that shape the organizing of collaboration. 
We combine the concept of meaning negotiations with that of counter-narratives to analyse how resistance - understood as discursive struggles over and during collaboration - may influence CG. We follow a definition of narratives as: "temporal, discursive constructions that provide a means for individual, social and organizational sensemaking and sensegiving” (Vaara, Sonenshein, \& Boje, 2016, p. 496). Two types of narratives have been identified as vital to understanding organizing processes of, for example, a collaborative initiative (Bartel \& Garud 2009, Grant \& Marshak, 2011; Pedersen \& Johansen, 2012): dominant, strategic narratives and counter-narratives. Strategic narratives are well-structured, with a clear plot, typically expressed by a spokesperson to establish a specific meaning, intention or goal as shared (Gabriel, 2000; Pedersen \& Johansen, 2012). Counternarratives, meanwhile, can be defined as "stories which people tell and live which offer resistance, either implicitly or explicitly, to dominant cultural narratives” (Frandsen et al., 2016, p. 2). These are often more fragmented and polyphonic, voiced in less structured everyday communication that helps to negotiate meanings, and to alter and resist a dominant narrative (Humle \& Pedersen, 2015; Vaara et al., 2016). Narratives, then, can communicate dominant, strategic goals and future directions; however, they can also counter and oppose such goals and directions by expressing alternative meanings, and it is therefore apt to examine counter-narratives when studying resistance.

The combination of these concepts allows us to investigate resistance dynamics as discursive struggles through negotiations of the meaning of dominant and counter-narratives about organizing collaboration. Instead of focusing on resistance in relation to either micro practices (Thomas et al, 2011) or macro perspectives (Thomas \& Hardy, 2011), this combination enables us to analyse resistance as emerging in various modes of communication in local work situations (e.g. in meetings or hallway conversations), and across time, space and actors (e.g. in e-mails, reports and agendas) (Grant \& Marshak, 2011). Based on this approach, we explore how meaning negotiations and counter- 
narratives influence the organizing of collaboration as a mode of governance in a case from the Danish ECE sector, described below.

\section{A case of collaboration in educational governance: research context and methods}

The context of our study is the policy area of ECE - a costly part of the Danish education sector, with $90 \%$ of 1-2-year-olds and $98 \%$ of 3-6-year-olds enrolled in daycare. The area is hierarchically organized: daycare centres are run by frontline education managers and staff, often organized in districts administered by district managers, who answer to an education department that supports a political committee at local government level. The local education departments are managed by a head of department (HoD) responsible for the overall budget and service quality, which are managed by administrative education consultants and enacted by education managers and staff (Plotnikof, 2016b; Plum, 2012, 2014). The local governments, in turn, follow the central legislation from the Danish Ministry for Children and Social Affairs, but they may also formulate local policies. Recently, collaborative initiatives have emerged to innovate the ECE sector using non-hierarchical means, and new national ECE legislation was developed (2015-2018) through stakeholder involvement.

In this case study, we followed a local government initiative to improve ECE policy and quality through multi-actor collaboration (see table 1, below). The local education department initiated this collaboration with the goal of developing ECE quality models inspired by visible learning and $21^{\text {st }}$ century skills (Hattie, 2008; Knudsen, 2017) in response to challenges of inefficient learning and a lack of technological innovation skills. They also argued that their initiative responded to a growing number of children with special educational needs, combined with fewer resources and larger daycare centres, as these issues represent a challenge to everyday pedagogical practice, demanding new skills of frontline staff and managers. The administration (HoD and education consultants) found that 
earlier governance initiatives had not included stakeholders to a satisfactory degree and had therefore not succeeded. In relation to the new national legislation, they wanted to improve local ECE policy and practice by including local stakeholders' visions and resources in a collaborative effort to develop a new model of education quality. The initiative was developed winter 2015/2016 and it first included collaboration with ECE managers (district and frontline managers) and trade union representatives, and later it was also planned to include staff, children and parents.

\section{TABLE 1}

We collected data during 2016 using ethnographic methods (A. R. Pedersen \& Humle, 2016; Plotnikof \& Zandee, 2016; Ybema, Yanow, Wels, \& Kamsteeg, 2009), including observations, audio and video recordings, photographs, minutes and graphics from planning meetings and collaborative events, and individual and group interviews about the ideals and challenges of the collaboration to improve ECE quality. These methods were used before, during and after activities in administrative and ECE settings to follow the emerging organizing of collaboration. Because most meetings were located in administrative offices, much of the data was collected here, while other data were compiled from ECE manager meetings, staff meetings, and collaborative events at daycare centres.

The data set consists of: audio recordings and observation notes from 10 planning meetings (2-3 hours duration), 4 ECE manager meetings (2 hours duration), 3 collaborative events on local interests in quality models (3-4 hours duration), 2 collaborative events on national interests in new quality models (3 hours duration), and 10 interviews (1-2 hours duration) with administrators, union representatives 
and ECE managers. In addition, one hour observations of everyday practice were conducted before and after all fieldwork encounters. The data set also includes e-mails, meeting agendas and minutes, graphic facilitation posters from planning meetings and collaborative events, and field notes and recordings of conversations that took place in the hallways during and between meetings. In terms of ethical considerations, we informed all participating stakeholders of our interest in the challenges of CG, including resistance, and guaranteed anonymity, which all participants accepted.

TABLE 2

Resistance emerged as a critical factor at an early stage of our fieldwork; as we found it largely overlooked in the literature on CG, our analytical approach drew on resistance studies. We analysed data through both inductive, empirically driven coding and deductive, theory-driven coding (James, 2012). First, we transcribed (interviews, meetings, hallway conversations etc.) and described (visuals, videos, photos, websites, field notes etc.) all data sources, highlighting accounts of resistance (e.g. struggles over what collaboration or quality is, who should be included, how to plan it, what to do, as well as embodied practices of dislike, frustration and opposition). Second, we developed an event timeline to create an overview of the data and follow how the organizing process of CG involved resistance across time, space and actors. Third, we reviewed the available literature to explore relations between empirical accounts and theoretical concepts of resistance, which led us to focus on resistance through meaning negotiations and counter-narratives. At the same time, we switched back and forth between the coding of isolated data sources and comparisons across the full data set. 
When zooming in on, for example, an interview describing the initiative, we looked at the previously identified empirical accounts of resistance (from step one); we followed how meaning negotiations and counter-narratives emerged around the initiative; and we explored issues such as what was seen as denoting collaboration and quality and what was not, why and how, by whom, and with what reactions, frustrations and discussions - who was constructed as 'for' or 'against'. We then zoomed out, comparing the detailed analyses of various events (by using the timeline) to strengthen and nuance them; for instance, which narratives are circulated in e-mails, who participated in a negotiation of meaning before attending another meeting related to the collaboration, which relations of powerresistance are indicated etc.. After repeating this process and cross-referencing different data sources to ensure analytical saturation, we identified three analytical clusters (see table 3).

\section{TABLE 3}

Table 3 illustrates the clusters: The first cluster encompasses examples of a dominant narrative of CG - highlighting the initiative as good, necessary and legitimate, with stakeholders constructed as interdependent and the clear purpose of improving ECE policy and practice through the implementation of a new quality model. Here, data from formal meetings, collaborative events, emails, agendas and interviews were a particular focus of analysis. The second cluster includes negotiations and counter-narratives surrounding the planning of the collaborative initiative, mostly communicated discretely amongst administrators, thereby constructing others as potentially resistant and forming an indirect resistance themselves. This expands the organizing of e.g. the actors, themes 
and events in a collaborative initiative to include multiple stakes. For this cluster, data from meetings, interviews, photographs and e-mails were used. The third cluster involves co-existing (counter)narratives that negotiate meanings of purpose and goal, both during collaborative events and, more subtly, in between such events. This destabilizes a dominant narrative of a new quality model and includes more voices in the planning and defining of future collaborations. For this cluster, we drew upon data from collaborative events, meetings, photographs, minutes and poster graphics.

The analytical clusters were not a priori analytical distinctions, but rather a choice we made along the way. The division between cluster two, 'prior to', and cluster three, 'during' collaboration, stems from the empirical accounts of the process, which we decided to keep in order to show how different modes of resistance emerged during various parts of the organizing process, as well as to unpack how different actors - both the administrators who had planned the initiative and other stakeholders - all reproduced and countered the dominant narrative. Below, we outline our findings, beginning with a brief example of 'the dominant narrative' (cluster one) before focusing on how resistance emerged in relation to this and influenced the organizing of the initiative (clusters two and three).

\section{Findings}

We present our findings in two parts. Firstly, we show how a dominant narrative regarding the initiative is challenged during meaning negotiations and by counter-narratives communicated by the planning team prior to collaborative events: sometimes by constructing 'others' as potentially resistant or 'always resisting'; sometimes through more implicit communication by the administrators themselves as they counter collaborative ideals of stakeholder inclusion. During this process, powerresistance relations between collaborative and hierarchical discourses are invoked, which challenges the planning of, e.g., stakeholder selection and themes, but influence the organizing of the initiative 
by encouraging the inclusion of multiple stakeholder interests. Secondly, we unfold how resistance is communicated - both explicitly and more subtly - during and between collaborative events through stakeholders' negotiations of the goals of a quality model. Here, tensions between hierarchical and collaborative discourses also challenge the process by unfixing the meaning of quality and collaboration, thereby also legitimizing alternative voices and expanding the scope of collaboration to include more stakeholders in the planning of future collaborative initiatives. The findings show that resistance is woven into the local government initiative in different ways through a shifting constellation of actors’ negotiations and counter-narratives regarding collaborative processes and purposes during different parts of such collaborative forms of governance.

\section{Speed bumps: Potential and indirect resistance prior to collaboration}

A dominant narrative surrounding the initiative concerns local ECE policy and ideals of developing a better local quality model focusing on pedagogical efforts to support children's development of $21^{\text {st }}$ century skills. This narrative is especially common among administrative staff within the local education department. Below, for example, it is voiced in a conversation between education consultants on the way to an initial planning meeting at city hall. In this narrative, one of the consultants constructs the need to develop ECEC quality by enhancing educational professionals' skills to deal with the challenges facing modern-day children. She legitimizes the purpose of the collaboration - improving quality - as for the sake of the children, and in so doing stresses stakeholder interdependence and the importance of involving ECE staff, who have a key role in driving and implementing the initiative.

Susan: We know we need better quality. So this goal could frame the ECE area, but how to accomplish it? All this talk about $21^{\text {st }}$ century skills - that kids today kids need different skills than previous generations - you know, cross-disciplinary innovation, teaching kids that instead of just doing tests. We are also thinking about their democratic 
education and citizenship [skills], right? But unlike in primary schools, we say that staff need skills-enhancement to deal with the pedagogical challenges of $21^{\text {st }}$ century skills, growing numbers of special needs children, bigger daycare centres - e.g. by participating in the development of new goals through these collaborations. It's no use if staff just receive instructions [...] we all need to be on board - they are the ones driving development and anchoring this!

During the planning process, various actors - primarily administrators (HoD and education consultants), but sometimes also politicians and ECE managers - communicate this dominant narrative about the need to collaborate on developing a better quality model through stakeholder inclusion. They do so during formal meetings with the political committee, in administrative meetings, meeting minutes, meeting invitations, and in e-mails to stakeholders (e.g. ECE managers and trade union representatives), thereby disseminating a dominant narrative that the local initiative, intended to develop a new quality model, is reliant on stakeholder collaboration.

This narrative, however, is also countered during the planning process, which involved a long series of meetings about which stakeholders to include, when, about what, and with what intended outcome(s) in terms of quality. These meetings took place in local government offices amongst the planning team (education consultants and the HoD). Although they initiated the idea of collaboration, the planning team also express resistance along the way. In struggles over stakeholder selection and over collaborative themes and processes, they construct both each other and others as potential resisters, as well as voicing more inconsistent, discrete counter-narratives, in which they themselves resist collaboration. On the way to a planning meeting with the HoD, one consultant says:

Nina: $\quad$ This won't go anywhere if we just suggest it to educational stakeholders. Then they'll just say, they are too busy. We need to organize it on a much larger scale [...] My big challenge is how to get them on board. I think a lot about how to sell it to them [...] It will be met with resistance. Susan [another education consultant] wants Nick [HoD] to participate - and of course he needs to participate, but I don't think he'll play an active role. He always excuses himself with stuff; he can't be bothered. But he could have an impact on getting others on board, right? If he says: "I support this, we are doing this". 
You know, I hope to get him on board, so he can tell them: "You have to participate, you can't say no".

Researcher: So you will try to use him strategically?

Nina: $\quad$ You bet, because I've tried to deal with their opposition before. It's a speed bump.

Here, Nina reconstructs the dominant narrative of co-creating better quality through collaboration which needs to be 'scaled up'. Nevertheless, she also constructs potential resisters to the collaboration - in this case educational stakeholders and the HoD, who in the dominant narrative are those driving the process. In 'selling it' to 'get them on board', she implies that ECE managers and staff will not participate automatically, although they should, according to the dominant narrative of improving ECE quality for the children's sake. She explicitly refers to their reactions as resistance that needs dealing with, despite the dominant narrative including them in the process of defining educational quality and enhancing their professional skills accordingly. Moreover, she also constructs the HoD as a potential resister - in terms of his passivity - and she contemplates how she can influence him, and thereby others, to avoid resistance. In this way, she constructs potential resistance and resisters as 'speed bumps', but she also indirectly counters collaborative ideals herself by negotiating ways of affecting - even manipulating - others . On one hand, she reaffirms a dominant narrative of collaboration; on the other, she counters ideals of including stakeholders on their own terms and with different interests in addressing a common issue. Moreover, she employs strategies using formal hierarchical power (via the $\mathrm{HoD}$ ) to demand collaboration, e.g. by giving the HoD particular tasks at the collaborative events so he cannot resist by cancelling or taking a passive stance. Thereby, she voices the dominant narrative, but also interweaves a counter-narrative of 'others' as potential resisters. At the same time, her approach to 'dealing' with others indicates indirect resistance; she wants to collaborate, but she also discreetly imposes hierarchical power into the collaboration, thereby invoking tensions between hierarchical and collaborative discourses during the planning process. 
Struggles over the planning of collaborative initiatives are also communicated more directly amongst the participating administrators (the HoD: Nick; education consultants: Susan and Nina), e.g., during planning meetings. Below, they discuss collaborative events and stakeholders (children and parents, the political committee, ECE managers, frontline staff, and unions). While the team reproduces the dominant narrative about co-creating a new quality model by including all stakeholders, they also negotiate who, how and why. During these negotiations, they both construct others as resisters, and they counter collaborative ideals themselves:

Nina: $\quad Y o u$ know, the idea of co-creation - that we need to collaborate along the way. I really

Nick: think it would be great if we could initiate that already in the planning stages.

Susan: That first meeting with ECE managers - that's the most important. Otherwise, they kill

Nick: it. You know we need to persuade them into thinking that it's good for them too. [Y]ou really need to sweet-talk them, so they don't see this initiative as a no-go.

Nina: Yeah, that's why we need you, because they always resist.

Nick:

But I can't sweet-talk them - I can beat them up! You are the ones who have to make them realize that this is great.

Nina: [sighing] Well, I had hoped you would beat them up.

Nick:

[laughing] But it's never going to be great then, right? If we start this by forcing them... We could go somewhere, just them and us, where we'll say: "We have this initiative to improve quality". You know, so they can't say yes or no, and then we include them in the planning somehow. Because if they don't like it...

Susan:

But the problem is always that they don't agree; there's always somebody who thinks it's crap when the rest of them like it.

20 Nick:

Yeah, and then we have the other stakeholders, like the unions. We know if they aren't included early on, they will never collaborate. They will say at every subsequent meeting: "Of course, it didn't work out because we weren't included."

21 Susan:

But we talked about meeting with them separately prior to the collaboration.

22 Nick:

Or maybe we should include them in the first event, although that's...

But that's doomed to fail, isn't it?

I don't know, we've never done that - we've done everything else. Imagine if they could wash away the reluctance of the ECE managers so they don't make a fuss!

Here, the team reconstructs the dominant narrative of stakeholder interdependence in pursuit of a new quality model, but during the first 10 lines, they also construct a counter-narrative, in which they 
position ECE managers as resisters, who will 'kill it'. Contrary to Nina's expectations in the previous exchange, the HoD is not himself opposed to collaborating, but he refuses to demand that others collaborate. In effect, they negotiate how to deal with potential resistance and others as resisters: the HoD returns to the dominant narrative, thereby placing responsibility on the consultants to 'sweet talk’ potential resisters. Although 'sweet talking' has a manipulative connotation, he refuses to use formal power (as HoD) to 'beat them up'. The consultants counter this by constructing ECE managers as 'always resisting', and hence in need of a 'beating' from a hierarchical power position. While the consultants often voice the dominant narrative of collaborative ideals, in the above extract they also counter such ideas by arguing in favour of using the HoD's formal power to 'beat up' potential resisters, thereby voicing tensions between collaborative and hierarchical discourses. In this case, the HoD overrules hierarchical discourses (albeit from his own loft position in the team hierarchy) by insisting on planning according to collaborative ideals. He includes additional stakeholders and their interests, which he legitimizes by pointing to the potential of social dynamics to affect resistance.

In this ways, administrators both reconstruct the dominant narrative and negotiate counter-narratives of 'others' as potential resisters, thereby also themselves resisting collaborative ideals. This infuses the planning with discursive struggles over the use of formal, hierarchical power to make others participate, or collaborative ideals of including stakeholders and giving them the right to voice their own interests, which challenges the organizing. As seen above, this influences the process, e.g. by including more stakeholders, and re-emerges in later conversations amongst the planning team, where 'resisters' are woven into the dominant narrative as driving forces:

Nina: $\quad$ We need them - they are driving forces [...] you know, reminding oneself that every time there's opposition, there's something at stake for the actors involved. Instead of just - because I get angry and annoyed. [B] ut this resistance is about something important. What is at stake for them? And how can we include it in a collaborative way? 
Such meaning negotiations between administrators communicate co-existing (counter-)narratives; both the dominant narrative of collaboration as a means of governance for co-creating a better quality model, for which stakeholders are needed; and counter-narratives, in which resistance, sweet-talking, and beating up are also voiced as potential strategies. Here, administrators explicitly construct 'others' as potential resisters and as always resisting, but in so doing, they themselves also implicitly resist collaborative ideals. In this case, however, constructing 'others' as resisters re-orientates the planning to include additional stakeholders and their interests in the collaborative events.

By unpacking meaning negotiations and counter-narratives, we see how discursive struggles occur during the planning of the initiative amongst administrators. Resistance dynamics emerge not so much as explicit opposition to the initiative, but more indirectly in the ways 'others' are constructed as potential resisters and the administrators' own implicit resistance in struggles over the use of hierarchical power rather than relying on collaborative ideals. Thereby, power-resistance relations appear between contradictory governance discourses of formal hierarchy and more network-oriented collaboration (Pedersen \& Hartley, 2008; Plotnikof, 2016b; Vangen, Hayes, \& Cornforth, 2015); for example, administrators voice collaborative ideals of including stakeholders, whose voices they regard as important, but also negotiate how to use formal power or manipulation. These discursive struggles complicate the organizing of the initiative, but rather than destroying it, they challenge planning decisions to include more stakeholders and orient themes addressed at collaborative events towards multiple interests. As such, different modes of resistance - e.g. as potential, or as indirect, explicit or implicit - are communicated in meaning negotiations and counter-narratives that influence the organizing process.

\section{What's the point? Explicit and discrete resistance during collaboration}


Whereas accounts of potential and indirect resistance emerge amongst the planning team prior to collaborative events, such accounts are also communicated during and between collaborative events. For example, at ECE manager meetings between collaborative events, the dominant narrative is both reaffirmed and countered:

Mary: $\quad$ There's the administrators, who really want to do this collaboration and improve quality. But I'm thinking - that it has to be combined with the rest of our initiatives [...] But so far we are not included in the planning, and we'll be collaborating with a lot of other people who work with other stuff, and we have bring it into life. So that's why I'm reluctant; you know, it's a confidence trick-they use our professional interest to include us in something we didn't ask for. Even if we might consider it important.

Liza: $\quad$ The idea is really good and useful in so many respects, educationally speaking...

Pat: $\quad$ But it needs to be combined with other initiatives, because otherwise it will die. We can't do it alone. The staff can't do it all -they need to see: 'What's the point?' or else it won't take root.

In this exchange, the ECE managers negotiate the purpose of collaboration in various ways: by questioning the need for the collaborative initiative - as ‘a confidence trick' they 'didn't ask for' thereby countering a dominant narrative that such collaboration responds to shared needs of interdependent stakeholders; and by reaffirming the dominant narrative that 'the idea is good', but then countering that their own and other educational stakeholders' insights into everyday educational quality and existing initiatives are not included in the planning. They challenge what 'the point' is and construct the risk that it 'will die' if staff cannot see the point. As such, these stakeholders counter the initiative as a collaboration responding to shared interests, and they question the planning of collaboration without including stakeholders' insights, arguing to redefine its purpose to fit with other initiatives. In this way, they communicate themselves and others as both the ones 'to bring it into life' and as potential resisters.

In addition to stakeholders' meaning negotiations surrounding the collaborative initiative in the form of various counter-narratives behind closed doors between collaborative events, resistance is also 
voiced more directly and explicitly during collaborative events. Such events often start with an administrator voicing the dominant narrative:

Nina: $\quad$ We want to start by stressing that we don't want this to be another branding project, but much more of a collaboration to enhance what we already do. [...] And I want to stress that this is to keep our focus on the education of kids, on the core educational tasks. And we're here to collaborate on improving ECE quality, and that needs to be central. And educational leadership is an important part of this and can set a course for this collaboration and our field of ECE [...] So it is pivotal that this collaboration is meaningful for us - all of you and the other frontline staff and managers. And that's important when setting our ECE goals and visions. So let's aim high and talk about what's at stake from our different positions to set a course and improve children's lives and education in the ECE sector.

Here, we see how the administrator frames the purpose of collaboration as improving ECE quality; as dependent on the ECE managers' engagement in relation to other actors; as involving shared meanings relating to the various actors' different positions; and as focusing on core tasks concerning children's education. In this dominant narrative, she stresses the importance that collaboration is 'meaningful' for all involved as a response to potential resistance; however, this collaborative discourse of 'meaningfulness' for all legitimizes stakeholders' negotiation of the purpose of collaboration, which they do during the initial collaborative events. During these negotiations, the administrator's stressing that the initiative is not merely a branding project becomes a point of resistance in counter-narratives regarding the purpose amongst other stakeholder groups. Stakeholders such as ECE managers and union representatives explicitly question whether, at the end of the day, the purpose of the initiative is not a branding exercise - for instance at a workshop, where an ECE manager (Mary) and the HoD (Nick) discuss this:

Mary: We're discussing a shared goal for this - and I'm thinking "Don't we have goals in the national legislation; do we need more?" Not that I'm against branding, but if that's what this is about, I want to know [laughing] That's fine, but then it's not about ECE quality.

Nick: $\quad$ For me, it's not about branding ourselves in relation to external parties, but about honing a shared direction; we have so many different educational initiatives and 
activities popping up [...] We need a shared vision for ECE that is meaningful for us all and relates to what we're already doing, and that can act as a guiding principle when new demands come along. But we need to define what we want - what's at stake in ECE here, what's our quality model?

Mary I'm not sure it will be better with more of a common goal or a new model that defines quality [rolling her eyes]; others will still interfere.

Nick: But if you [to everyone] want to exert an influence on the strategic direction of this policy area, you have to engage with this; you can't say afterwards: "Why weren't we involved?" So, we have to do it, in this group - this is it - the management of this policy area is now!

In such collaborative encounters, resistance is communicated more directly between two stakeholder groups that negotiate the purpose of collaboration - 'a shared goal, vision, model'. Initially, the dominant narrative is countered by Mary's account of a potential hidden 'branding' agenda, which makes Nick reconstruct the purpose as improving ECE quality. Then Mary counters the need to create shared goals and questions the practical effects of centrally defined quality models. This scepticism is not rejected by the HoD, but is instead met with the dominant narrative of collaboration as a way of influencing and innovating the policy area of early childhood education. Lastly, the HoD also attends to potential resistance from other stakeholders, stressing that the invitation to co-create better quality demands stakeholders’ engagement now, rather than later.

In this struggle, the HoD constructs the collaborative purpose of a quality model, but when this is challenged by resisting voices, he uses his formal, hierarchical power to discursively demarcate what is negotiable (their influence) - and what is not (a quality model). Here, tensions between collaborative and hierarchical discourses are invoked as administrators, on one hand, invite stakeholders to collaborate towards a meaningful goal while they, on the other hand, push their own agenda of what is meaningful (e.g. a quality model) by referring to strategic influence on policy. This makes stakeholders aware of a formal hierarchy, in which the HoD has a privileged position, and in which other stakeholder groups may gain influence if they follow this narrative. Here, we see 
resistance to the initiative, both directly communicated between stakeholder groups such as ECE managers and administrators, and implicitly communicated in administrators' struggles to juggle collaborative and hierarchical discourses when responding to the resistance of others.

Meanwhile, resistance during collaboration also occurs in more subtle ways. At ECE manager meetings held between collaborative events, the new quality model is discussed and ECE managers negotiate whether or not they should voice a shared opposition to the model at the next collaborative workshop. They decide not to; however, a couple of them subsequently decide to back each other up in countering a specific quality model, which they do at following events by arguing that: "If this is a real collaboration, we should all have a say in what the point is - what quality is - as a meaningful goal to strive for". Thereby, they employ collaborative discourses to challenge the dominant narrative. As such, tacit counter-narratives regarding the initiative also affected more direct meaning negotiations with both administrators and other stakeholders, e.g. by enabling them to voice their own right to have their say and counter a specific quality definition via face-to-face encounters during collaborative workshops. More discreet opposition appears amongst union representatives too, who likewise question the purpose of and need for a quality model, e.g., in breaks and between collaborative events. Here, competing meanings ascribed to the purpose of collaboration and of developing a quality model are discussed, and they criticize a quality model as the only purpose and the idea that all stakeholders necessarily share a singular goal. Instead, they articulate a counternarrative about co-existing but different goals defined by various stakeholders and contexts affected by the initiative. After the second collaborative event, the union representatives, alongside a few ECE managers, decide to demand that they are given the opportunity to participate in the definition of purpose and the setting of goals for the collaboration and in planning future events. Thereby, they counter the dominant narrative of a quality model as a predefined purpose and respond to the HoD's 
stressing of formal hierarchy by invoking collaborative discourses of 'having the right to speak', which enables them to participate in defining the conditions for the collaboration.

In this way, more discrete negotiations and counter-narratives can offer resistance to predefined goals, postponing formal decisions regarding the implementation of a quality model and legitimizing other voices in organizing collaboration. This is also apparent in the minutes reporting on the collaborative events, which are illustrated by a graphic designer in the form of a poster. The minutes illustrate the resistance to a new quality model defined in relation to a visible learning paradigm by reporting counter-narratives about other definitions of quality and collaborative purposes, and by adding a big red question mark on the poster next to the heading ' $\mathrm{A}$ new quality model' to be addressed at subsequent collaborative events. In effect, a new planning team is established, including stakeholder representatives, to co-create ideas for future collaborative events.

We have explored the emergence of resistance in various negotiations of meaning and counternarratives - sometimes communicated directly at meetings, collaborative events and in minutes, and sometimes more discretely in hallways and behind closed doors. However, instead of destructing the initiative, these discursive struggles challenge the dominant narrative's predefined plans - by disclosing collaborative purposes and quality definitions that exclude certain stakeholder interests, and by altering the planning of possible future collaborative events to include a broader spectrum of voices and extending the collaborative processes. This invokes power-resistance relations between hierarchical and collaborative discourses. For instance, administrators invite stakeholders to collaborate towards a meaningful goal, yet they also seek to predefine this goal; or, as in the case of the HoD, stress the formal hierarchy as a power construct, underlining how collaboration may influence proceedings by co-creating a shared strategy, but also push back against resistance by reminding others of his own formal position of power within the hierarchy. However, stakeholders counter administrators' definitional power and demand that others are included in organizing future 
events. Thus, discursive struggles emerge as stakeholders challenge the organizing and purpose of collaborative events, and become an inherent part of the collaboration that co-exists with other governing discourses, such as hierarchical discourses, as stakeholders' communication becomes infused with competing governance ideals.

\section{Discussion and conclusions}

This paper presents a dynamic understanding of resistance to collaborative forms of governance (CG), using a case from the field of early childhood education (ECE) in Denmark. We have argued to view resistance as a discursive struggle over meanings and practices of collaborative forms of governance, instead of a destructive matter to overcome (Kumar et al., 2007). Our approach focuses on meaning negotiations and counter-narratives emerging in everyday, naturally occurring communication to explore how resistance, in different ways, is woven into the organizing of collaboration between various actors who work together over a period of time to create solutions to public problems. Thus, we attend to resistance not just as direct opposition between individuals or organizations, but as embodied in diverse modes of communication prior to and during collaboration. This highlights that resistance in terms of discursive struggles influence the organizing of CG in multiplex ways, and thus are key to better understanding such form of governance (Hardy et al., 2005).

More specifically, our findings illustrate how resistance emerges both directly and indirectly, collectively and individually, in discursive struggles over the organizing of a collaborative governance initiative in the Danish early childhood education sector. First, we unpacked how a dominant narrative surrounding the initiative was challenged by negotiations of the planning of collaboration amongst administrators, who sometimes constructed others as potential resisters and sometimes themselves resisted collaborative ideals. This influenced formal decisions in terms of 
stakeholder selection and collaborative themes by expanding the collaboration to include multiple interests. Second, we unfolded how resistance emerged during and between collaborative events through negotiations and counter-narratives of collaborative purposes, thereby destabilizing the purpose of a new quality model, which challenged the dominant narrative of collaboration and extended the collaborative process. During the initiative, power-resistance relations between collaborative and hierarchical governance discourses created tensions, but they also legitimized multiple voices in the local implementation of collaboration. As such, resistance both complicated and co-constructed multiple voices and interests of the local collaborative encounters.

Although based on a case study, our analysis provides empirical knowledge about the resistance dynamics that can emerge in everyday work related to organizing CG, a governance mode considered important not only in Denmark but also internationally (Bryson et al., 2015; Koschmann et al., 2012; O’Leary \& Vij, 2012). In responding to complex problems, CG are likely rife with conflicting interests that may be considered detrimental to the co-creation of innovative solutions and public value. Our study, however, depicts collaboration and resistance as frequently entangled when organizing CG; by following meaning negotiations and counter-narratives, we shift the view of resistance from destructive misbehaviour (Kumar et al, 2007) to ongoing discursive struggle, thereby avoiding essentializing resistance or attaching it to specific actors. Our approach, thus, acknowledges multiple, even conflicting, collaborative accounts (Buchanan \& Dawson, 2007; Hardy et al., 2005), which may become the very resources that are intended to co-create solutions in CG (Hartley et al., 2013; Vangen \& Huxham, 2012). Such a perspective invites governance actors to (self-)critically reflect on not just the complicating, but also constructive, aspects of resistance in relation to the (counter-)narratives they themselves take part in, and on how those may predefine others as being 'for' or 'against' collaboration, which indeed can stigmatize certain actors or organizations and trouble potential collaborative encounters. 
As such, our study offers theoretical and analytical insights into governance studies of collaborative challenges. Whereas extant studies of CG have advanced theory on collaborative barriers and paradoxes (Cinar et al., 2019; O’Leary \& Vij, 2012; Vangen \& Huxham, 2012), tensions and power (Dewulf \& Elbers, 2018; Purdy, 2012; Vangen \& Winchester, 2013), we combine discourse concepts for studying resistance in a detailed analysis of the meaning negotiations and counter-narratives in everyday governance work. This analytical approach, unpacking micro-accounts of the role of resistance, highlights the complex fragmentation and interweaving of communication invoking power-resistance relations between e.g. hierarchical and collaborative discourses, intentional or not. This is important if we are to better understand the generative, productive functions of resistance dynamics in collaboration; as such, this study also complements the few existing studies of discourse within CG (Hardy et al., 2005; Mangan et al., 2018; Purdy, 2012). In extension to these, we highlight that resistance in CG is not a question of accepting or rejecting collaborative ideals, or opposing a planned, linear process that develops solutions to be implemented (Kumar et al, 2007); rather, we show that CG are much more fragmented and precarious.

Finally, this study also compliments resistance studies on discourse and counter-narratives (Frandsen et al., 2016; Putnam \& Nicotera, 2010; Thomas et al., 2011). Not by either celebrating or demonizing resistance (Thomas \& Hardy, 2011), but by combining concepts to analyse accounts of its dynamic emergence in various communication modes - direct and indirect, as well as tacit and implicit (Mumby et al., 2017) - which influence the organizing of collaboration across time, space and actors. This expands the scope of discourse studies on resistance to the field of governance; our combination of the concepts of meaning negotiations and counter-narratives offers analytical tools for studies (Humle \& Pedersen, 2015; Vaara et al., 2016) highlighting the role of different (counter-)narratives within governance contexts. 
Rather than idealizing CG as shared, consensus-driven processes, this study stresses the fragmented, even contradictory process of organizing such, in which varying modes of resistance - understood as discursive struggles that destabilize dominant meanings and practices - may become constitutive. Future studies could explore resistance dynamics in collaborative forms of governance with a particular focus on the formal and informal aspects of their organizing, or even in terms of their disorganization.

\section{References}

Ansell, C., \& Gash, A. (2008). Collaborative Governance in Theory and Practice. Journal of Public Administration Research and Theory, 18(4), 543-571. Retrieved from http://www.jstor.org/stable/pdf/25096384.pdf

Ansell, C., \& Torfing, J. (2014). Public Innovation Through Collaboration and Design. New York: Routledge.

Bryson, J. M., Crosby, B. C., \& Stone, M. M. (2015). Designing and Implementing Cross-Sector Collaborations: Needed and Challenging. Public Administration Review, 75(5), 647-663. https://doi.org/10.1111/puar.12432

Buchanan, D., \& Dawson, P. (2007). Discourse and Audience: Organizational Change as MultiStory Process. Journal of Management Studies, 44(5), 669-686. https://doi.org/10.1111/j.1467-6486.2006.00669.x

Cinar, E., Trott, P., \& Simms, C. (2019). A systematic review of barriers to public sector innovation process. Public Management Review, 21(2), 264-290. https://doi.org/10.1080/14719037.2018.1473477

Dewulf, A., \& Elbers, W. (2018). Power in and over Cross-Sector Partnerships: Actor Strategies for Shaping Collective Decisions. Administrative Sciences, 8(43), 1-15. https://doi.org/10.3390/admsci8030043

Emerson, K., Nabatchi, T., \& Balogh, S. (2012). An Integrative Framework for Collaborative Governance. Journal of Public Administration Research and Theory: J-PART, 22(1), 1-29. https://doi.org/10.2307/41342607

Erkama, N. (2010). Power and resistance in a multinational organization: Discursive struggles over organizational restructuring. Scandinavian Journal of Management, 26(2), 151-165. https://doi.org/10.1016/J.SCAMAN.2010.02.002

Erkama, N., \& Vaara, E. (2010). Struggles Over Legitimacy in Global Organizational Restructuring: A Rhetorical Perspective on Legitimation Strategies and Dynamics in a Shutdown Case. Organization Studies, 31(7), 813-839. https://doi.org/10.1177/0170840609346924

Foucault, M. (1980). Power/knowledge. London: The Harvester Press, Limited. 
Foucault, M. (1994). Power: Essential Works of Foucault 1954-1984, Vol. 3. Editions Gallimard.

Frandsen, S., Kuhn, T. R., \& Lundholt, M. W. (2016). Counter-Narratives and Organization. Routledge. https://doi.org/10.4324/9781315681214

Grant, D., \& Marshak, R. J. (2011). Toward a Discourse- Centered Understanding of Organizational Change. The Journal of Applied Behavioral Science, 47(2), 204-235. Retrieved from http://journals.sagepub.com/doi/pdf/10.1177/0021886310397612

Hardy, C., Lawrence, T. B., \& Grant, D. (2005). Discourse and Collaboration: The Role of Conversations and Collective Identity. The Academy of Management Review, 30(1), 58-77. https://doi.org/10.2307/20159095

Hartley, J., Sørensen, E., \& Torfing, J. (2013). Collaborative innovation: A viable alternative to market- competition and organizational entrepreneurship. Public Administration Review, 73(6), 821-830.

Hattie, J. (2008). Visible Learning. Oxon and New York: Routledge. https://doi.org/10.4324/9780203887332

Humle, D. M., \& Pedersen, A. R. (2015). Fragmented work stories: Developing an antenarrative approach by discontinuity, tensions and editing. Management Learning, 46(5), 582-597. https://doi.org/10.1177/1350507614553547

Huxham, C., \& Vangen, S. (2000). Ambiguity, complexity and dynamics in the membership of collaboration. Human Relations, 53(6), 771-806.

James, A. (2012). Seeking the analytic imagination: reflections on the process of interpreting qualitative data. Qualitative Research, 13(5), 562-577. https://doi.org/10.1177/1468794112446108

Knudsen, H. (2017). John Hattie: I'm a statistician, I'm not a theoretician. Nordic Journal of Studies in Educational Policy, 3(3), 253-261. https://doi.org/10.1080/20020317.2017.1415048

Koschmann, M., Kuhn, T. R., \& Pharrer, M. (2012). A Communicative Framework of Value in Cross-Sector Partnerships. Academy of Management Review, 37(3), 332-354.

Kumar, S., Kant, S., \& Amburgey, T. L. (2007). Public Agencies and Collaborative Management Approaches: Examining Resistance Among Administrative Professionals. Administration \& Society, 39(5), 569-611. https://doi.org/10.1177/0095399707303635

Mangan, A., Thomas, R., Davies, A., \& Gasper, R. (2018). The challenges of police-community collaboration: identity manoeuvres and power struggles in a neighbourhood based meeting. Public Management Review, 20(9), 1353-1373. https://doi.org/10.1080/14719037.2017.1383718

Mumby, D. (2005). Theorizing Resistance In Organization Studies A Dialectical Approach. Management Communication Quarterly, 19(1), 19-44. https://doi.org/10.1177/0893318905276558

Mumby, D., \& Plotnikof, M. (2019). Organizing Power and Resistance: From Coercion, to Consent, to Governmentality. In J. McDonald \& R. Mitra (Eds.), Movements in Organizational Communication Research: Current Issues and Future Directions. New York: USA: Routledge.

Mumby, D., Thomas, R., Martí, I., \& Seidl, D. (2017). Resistance Redux. Organization Studies, 38(9), 1157-1183. https://doi.org/10.1177/0170840617717554 
O’Leary, R., \& Vij, N. (2012). Collaborative Public Management. The American Review of Public Administration, 42(5), 507-522. https://doi.org/10.1177/0275074012445780

Osborne, S. P. (2006). The New Public Governance? Public Management Review, 8(3), 377-387. https://doi.org/10.1080/14719030600853022

Pedersen, A. R., \& Humle, D. M. (2016). Doing organizational ethnography. In Doing Organizational Ethnography (pp. 1-14). https://doi.org/10.4324/9781315677279

Pedersen, D., \& Hartley, J. (2008). The changing context of public leadership and management. International Journal of Public Sector Management, 21(4), 327-339. https://doi.org/10.1108/09513550810880214

Plotnikof, M. (2015). Negotiating collaborative governance designs: a discursive approach. The Innovation Journal, 20(3), 1-20.

Plotnikof, M. (2016a). Changing market values? Tensions of contradicting public management discourses: A case from the Danish daycare sector. International Journal of Public Sector Management, 29(7), 659-674. https://doi.org/10.1108/IJPSM-02-2016-0027

Plotnikof, M. (2016b). Letting go of Managing? Struggles over Managerial Roles in Collaborative Governance. Nordic Journal of Working Life Studies, 6(SI), 109-128. https://doi.org/10.19154/njwls.v6i1.4888

Plotnikof, M., \& Zandee, D. (2016). Meaning negotiations of collaborative governance: A discourse-based ethnography. In A. R. Pedersen \& D. M. Humle (Eds.), Doing Organizational Ethnography (pp. 137-159). New York: Routledge. https://doi.org/10.4324/9781315677279

Plum, M. (2012). Humanism, administration and education: the demand of documentation and the production of a new pedagogical desire. Journal of Education Policy, 27(4), 491-507. https://doi.org/10.1080/02680939.2011.640944

Plum, M. (2014). A 'globalised' curriculum - international comparative practices and the preschool child as a site of economic optimisation. Discourse: Studies in the Cultural Politics of Education, 35(4), 570-583. https://doi.org/10.1080/01596306.2013.871239

Prasad, P., \& Prasad, A. (2000). Stretching the Iron Cage: The Constitution and Implications of Routine Workplace Resistance. Organization Science, 11(4), 387-403. https://doi.org/10.1287/orsc.11.4.387.14597

Purdy, J. M. (2012). A Framework for Assessing Power in Collaborative Governance Processes. Public Administration Review, 72(3), 409-418. https://doi.org/10.2307/41506783

Putnam, L. L., \& Nicotera, A. M. (2010). Communicative constitution of organization is a question: Critical issues for addressing it. Management Communication Quarterly, 24(1), 158-165. https://doi.org/10.1177/0893318909351581

Thomas, R., \& Hardy, C. (2011). Reframing resistance to organizational change. Scandinavian Journal of Management, 27(3), 322-331. https://doi.org/10.1016/j.scaman.2011.05.004

Thomas, R., Sargent, L. D., \& Hardy, C. (2011). Managing Organizational Change: Negotiating Meaning and Power-Resistance Relations. Organization Science, 22(1), 22-41. https://doi.org/10.2307/20868845

Vaara, E., Sonenshein, S., \& Boje, D. (2016). Narratives as Sources of Stability and Change in Organizations: Approaches and Directions for Future Research. The Academy of Management Annals, 10(1), 495-560. https://doi.org/http://dx.doi.org/10.1080/19416520.2016.1120963 
Vangen, S., Hayes, J. P., \& Cornforth, C. (2015). Governing cross-sector, inter-organizational collaborations. Public Management Review, 17(9), 1237-1260. https://doi.org/10.1080/14719037.2014.903658

Vangen, S., \& Huxham, C. (2012). The Tangled Web: Unraveling the Principle of Common Goals in Collaborations. Journal of Public Administration Research and Theory: J-PART, 22(4), 731-760. https://doi.org/10.2307/23321340

Vangen, S., \& Winchester, N. (2013). Managíng Cultural Diversity in Collaborations: A Focus on Management Tensions. Public Management Review, 16(5), 686-707. https://doi.org/10.1080/14719037.2012.743579

Ybema, S., Yanow, D., Wels, H., \& Kamsteeg, F. (Eds.). (2009). Organizational Ethnography: Studying the Complexity of Everyday Life. London: SAGE Publications Ltd. 